\title{
Sdaa: Towards Service Discovery Anywhere Anytime Mobile Based Application
}

\author{
Mehedi Masud \\ Computer Science Department \\ Taif University \\ Taif, Saudi Arabia
}

\begin{abstract}
Providing on-demand service based on customers' current location is an urgent need for many societies and individuals. Specially, for woman, elderly people, single mother, sick people, etc. Considering the need of providing localized services, this paper proposes a mobile application framework that allows an individual to receive services from his neighborhood peers anywhere anytime. The application allows an individual to find and select reliable service providers near his location. The application will provide an opportunity to the interested individuals to use their free time for providing services to the community and earn some extra money. This application will benefit many stakeholders like elderly people, women at home, a person while traveling in an unknown place, etc. A prototype application is developed and empirical evaluation is considered to find the qualitative measures of the users' acceptability and satisfaction of the application. It is observed that users' satisfaction is high.
\end{abstract}

Keywords-mobile application; service discovery; mobile services; software engineering

\section{INTRODUCTION}

With the fast advancement of mobile computing technology current society is growing so fast having the ability to keep in touch with families and friends, search information in the internet, shop online without going physically to the shopping mall, learn using e-learning system, receive health services using e-health system, and search for daily needed searches, in variety ways using mobile devices and applications. Advances in the mobile technology has made our society more dependable on mobile and smart devices [1] and we cannot function without these devices. Mobile devices and applications play central rule to bring together the service providers and service users anywhere anytime. Over the past years, mobile application users have increased rapidly to look for various services from a mobile device.

Diverse necessities and demands of various services by citizens in nearly all aspects of daily life have fueled the use of Internet and mobile applications. Through the applications a consumer can shop, book appointment, communicate with peers, reserve tickets, etc. sitting at home, workplace, or while travelling with a computer or mobile devices. However, facility to look for on-demand service providers for our daily needed services (e.g., personal care, home service, food prepare and delivery, drop and pickup services, etc.) around the vicinity to our present location is still unavailable through mobile and internet applications. Still, social contact is needed to find reliable service providers. In our daily life we need diverse services. Service may include home cleaning, buying groceries, delivery of foods, giving a ride, fixing a car on demand, etc.

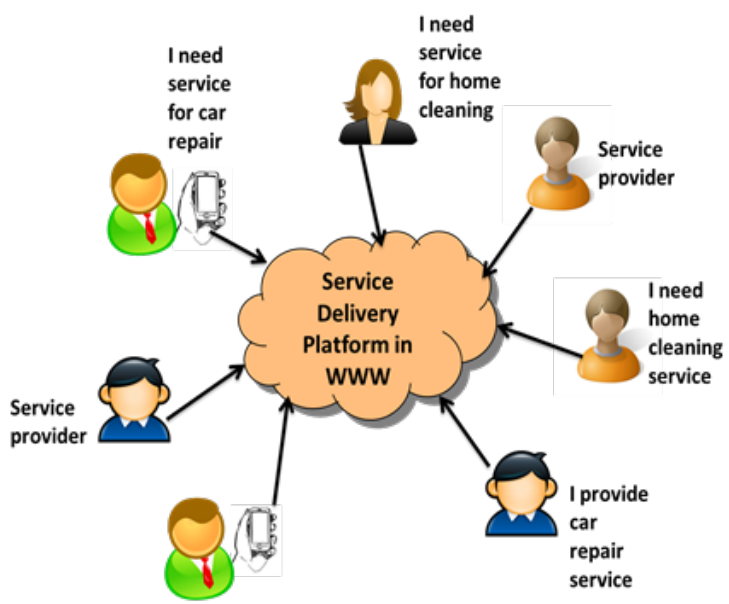

Fig. 1. The location based service providing scenario

For example, Mr. John is driving in a new city. Suddenly the car has a problem while driving. If there exists any application that provides a list of car service servicers nearby his current location then he can easily get help from the service providers even he is new in the city. This is called location based service. The scenario is presented in Fig. 1.

Location Based Service(LBS) is gaining popularity from the services of mobile devices that is dependent on the user's geographical location for providing needed services to the clients. The location based service (LBS) uses the present physical location information of users. This physical location is used as a "filter" for providing services to the users and delivering important information about a particular area related to the users' position. There are mainly two types of LBS [2, 3]. Type 1 is a pushed based services. In pushed base service an application service provider triggers services when a user reaches in a particular location. Example of these services include push business advertisements when a user enters in a market or show weather information when enters into a city, etc. In type 2, pull based services, services are triggered when a user requests an specific service. 


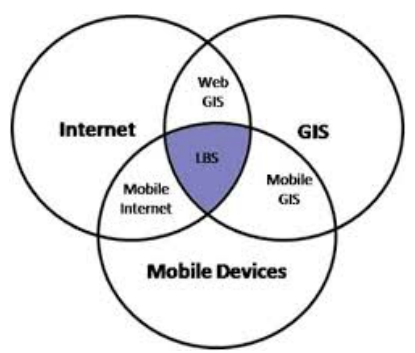

Fig. 2. Local based service architecture [6]

LBS provides services based on present location and time as well as based on the users' demands at a specific location [18]. Also the LBS system is aware of the needs of users and is able to map it to the location of the service requester. Since the mobile devices are becoming popular day by day, Mobile Location Based Service (MLBS) on the devices are expected to be a better profitable chance to the mobile service providers [19].

Exploiting mobile applications in portable devices, like smart phone, PDAs, tablet, etc. and LBS, daily needed service discovery around users vicinity can be provided to the service requesters even though the requesters move. Moreover, advances in information and communication technology have enabled service providers and requesters in the community to connect each other virtually wherever the users are located. Mobile apps help to create link between service providers and service requesters in the community.

The main goal of this paper is to propose a mobile application framework that identifies services and service providers using location based services. The need of service requesters is the central in developing the application that provides access to services when and where they need them. In the following the main goals of the proposed application are presented:

- Identify service providers and skillful persons in the neighborhood.

- Share skills among the people in the community instead of hiring people from company.

- Develop economy condition of jobless person however have skills

The rest of the paper is organized as follows. Section II discusses related works. Section III discusses the proposed application model. Section IV shows evaluation results and paper is concluded in Section V.

\section{LITERATURE REVIEW}

The conventional business model is changing gradually with the advancement of technology. Technological advancement facilitating the business model to reach to more markets and becoming more convenient and flexible. An example of this is the car rental company "Car2Go" [9]. The company provides its members a mobile application. Members use their Smartphone, tablet or computer to find nearby access to individual mobility through a large quantity of rental cars that are distributed across cities.
Peerby [10] is a web-based system that matches people that are in temporary need of a specific thing, with those that are in possession of the thing and are willing to lend it. Through Peerby people share (for free) their possessed items online. Members that are in need of a specific item, such as a ladder, post their item request and location through the system. The member who possesses the item and is willing to lend or share the item, and is located in a close enough vicinity of the person in need, can contact through the system. Both members living in the same neighborhood can now agree on the manner of transfer of the item.

Shareyourmeal [11] is an online application that provides "homemade foods" with the opportunity to sell their home made meals to the interested neighbors. Members of Shareyourmeal can find out that their neighbor, a talented home cook, is interested to sell homemade food that the member is interested to take. This helps community people to share cooking takeaway meals each other. The company has developed an online platform through which home cooks, willing to sell portions of meals, and neighbors in need of healthy takeaway food, can get in touch. It not only share foods, but by having neighbors visit each other for picking up takeaway food, it also helps to create trust between strangers in a neighborhood.

Sorted[12] is an online platform through which individual can sell his services to the interested parties. A sorter (service provider) can indicate the tasks he/she can conduct, hourly rate and the distance he/she is willing to travel for conducting the service [13]. The platform matches individuals that are able to provide a certain service with parties that are in need of such a service. The platform was first demand driven. Individuals could post a service request on the online platform, and wait for sorters with the relevant skills to reply.

Fixura [14] is an online peer-to-peer platform for lending and borrowing money. It provides platform to lenders and borrowers the way the clients want to lend out or borrow money. The system also matches lenders and borrowers with each other. The system provides facility to both lenders and borrowers to set the specific criteria against they want to respectively lend or borrow money. In order to lend money a borrower indicates the amount of money he/she wants to lend, the duration of the loan and the interest rate. The borrower also provide some contact information. To lend money lenders search for loan requests and assemble their investment portfolio.

Airbnb[15] is an online platform through which peers can list, discover and book unique spaces (accommodation), all made available by other peers [11].

TaskRabbit [16] is an online platform through which both peers and companies can post task they would like to "outsource" to peers that are willing and able to do these. The person that posts the task can set the price he/she is willing to pay and choose a suitable TaskRabbit from the people who bid on the task. It mainly connects neighbors in order to get all sorts of tasks and errant done, was born. The platform works similarly like Sorted, with the essential difference that this one is demand-driven, whereas Sorted is supply-driven. 
This demand-driven orientation is depicted by the illustration above, which shows that the person who posts a task is in charge (e.g. of price setting, selecting a TaskRabbit and describing the service to be delivered).

Most of these companies function through an online platform or marketplace that connects consumers that own certain assets and skills with consumers in temporary need of those. These companies can facilitate peer-to-peer markets for potentially all product or service owned by consumers. This business model might become particularly disruptive to conventional rental solutions for mobility, accommodation, catering and other sorts of services, because it is able to serve the same needs at a significantly lower price. Moreover, it empowers consumers to capitalize on their property and skills, providing them with an opportunity for micro-entrepreneurship and lowering total cost of ownership.

\section{SYSTEM MODEL}

This section discusses the architecture of the mobile application "SDAA". The framework is shown in Fig. 3. In order to request a service or to provide a service users have to register into the system. Once a user registers he/she can post a request, see the requested services, and bid a service request. Both requester and provider can indicate the specific criteria against which they want to respectively consider or provide service. Through the system, a provider can indicate the amount of money he/she wants for the service, the duration of the service delivery to the provider. A requester can also see all the service providers' bids and select the desired service provider by analyzing the providers' portfolio. The system allows an user to search and receive services at anywhere and anytime from the user's current location. The system also allow individuals to receive services with disabilities, woman at home, individual at work, family in travel, friends in amusement parks, etc. The important services may include:

- Personal Assistant (PA): Delivers assistance to personal care, household jobs, and patient care with permission of a doctor. PAs are selected by individual customers. The individual will select PAs through checking service provider profiles, reputation, experience and remuneration issues.

- Home Delivered Foods: Provided to individuals who cannot go outside to buy food or prepare food at home. With this service an individual can ask for services to deliver food on this request.

- Home Delivered Shopping: An individual can ask for a service to shopping on behalf of him. The individual may be at home or at work does not have time to go for shopping or is sick.

- Drop-Pickup: An individual may get service for drop and pickup to office, school, market, airport, etc. if the person does not have car.

Service providing mechanism using the application is described elaborately in the following.

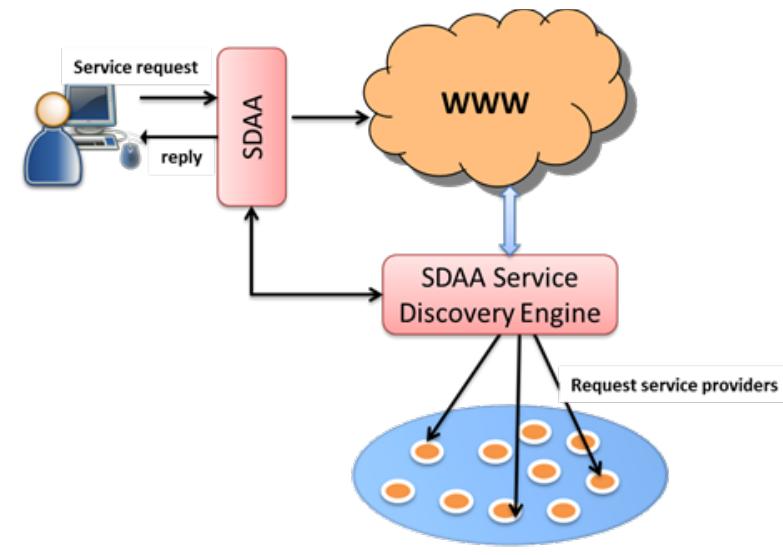

Fig. 3. SDAA Architecture

A. How are services provided?

An individual may receive service through the following steps:

1) Register to the system with the details of personal information. Mobile no is the key information to identify the current location of the individual and to find nearby service providers.

2) The client must post his service request by selecting the category of service request.

3) The client must mention the following constraints to receive better service.

- Time duration to deliver service from the time of request.

- Pickup from service provider or delivery to the individual

- Payment method. (Cash, Bank transfer, etc.)

- Payment amount.

4) A service provider may be individual or a company to provide services to a service requester.

5) A service provider must register to the system to provide services. Service providers must provide personal information to attract the service requesters and to verify the identity of the person.

6) After becoming a member the service provider can see the list of services with the following criteria.

- Distance from present location

- Types of service

- Service amount

B. How a service request is submitted and select a suitable service provider?

B.1 Online service Request

1) A service requester first login into the system.

2) Select type of service needed. 


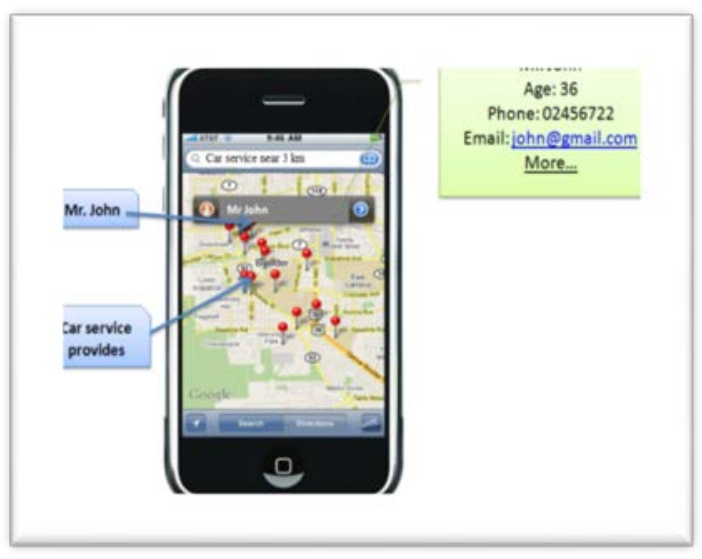

Fig. 4. Car service request scenario

3) Define the constraint of the service request.

4) Find service providers for the requested service over the map.

5) Select a service provider.

6) Make connection with the service provider for service execution.

7) Give feedback of the service.

B.2 Offline Service Request

1) A service requester first login into the system.

2) Select type of service needed.

3) Define the constraint of the service request.

4) Search for service providers for the requested service over the map.

5) If no service provider is available then the request is posted in the service request pool. In this case the service requester must put the details of the service and the constraint.

6) The request will be removed from the service request pool after the defined time.

B.3 Select a Service Provider.

1) Make connection with the service provider for service execution.

2) Give feedback of the service.

\section{An Example Scenario}

Consider a scenario of car fixing problem. Mr. John is driving in a new city. Suddenly the car has a problem while driving. Mr. John opens the application and post a request for car fixing. The system automatically detects his present location and broadcast his request to the car service providers near his current location. The application scenario is presented in Fig. 4. The system allows to search for service providers with the distance and time range. Car service providers within the range of $3 \mathrm{KM}$. Fig. 5 shows the service providers names within the range of $3 \mathrm{KM}$ and Fig. 4 shows the names of the service providers with the time range. When John selects any service provider he can find the details of the service provider. After reviewing the profile of a service providers John can make a direct contact with the provider for solving the problem.

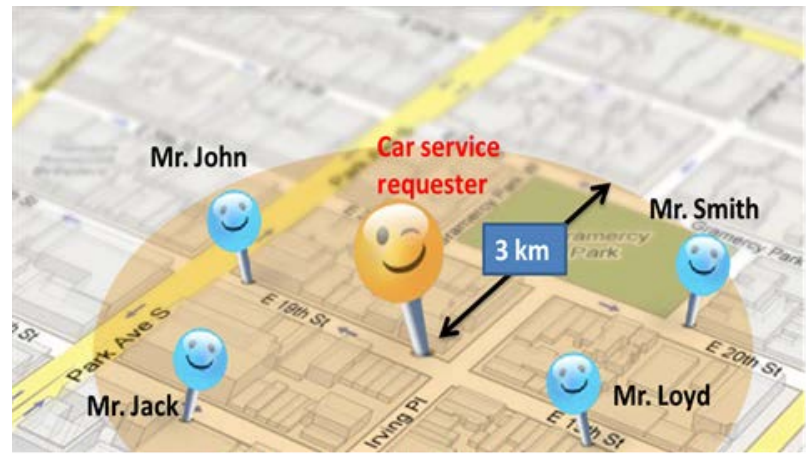

Fig. 5. Car service providers within the range of $3 \mathrm{KM}$ Car service providers within the range of time limit

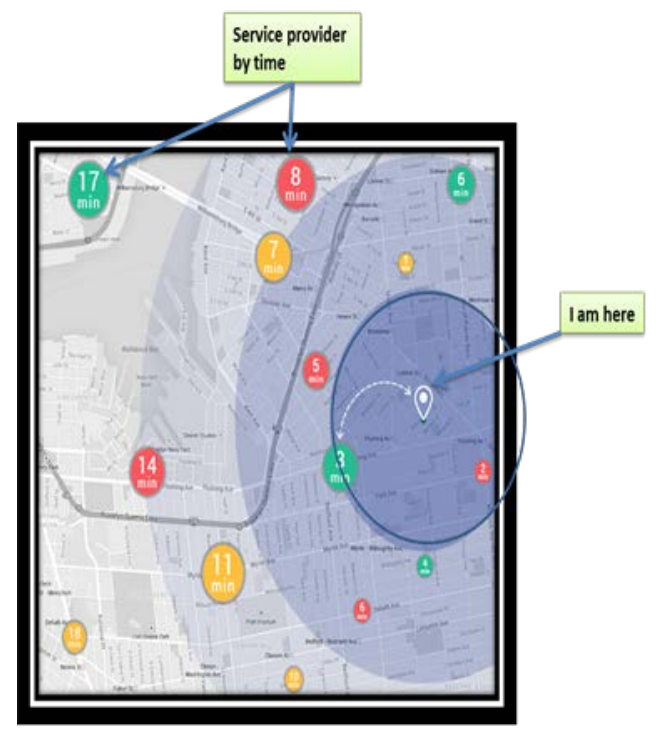

Fig. 6. Car service providers within the range of time limit

\section{IMPLEMENTATION AND RESULT}

This section discusses the prototype implementation of the proposed mobile application and User acceptability evaluation of the system. For user acceptability evaluation user acceptability is measured using the Ubiquitous Computing Acceptance Model (UC-AM) [17, 4]. The obtained results show the acceptability of the proposed application. It is observed that the users' satisfaction is high. Users' experience is the most important target for any application. Therefore, understanding the requirements and characteristics of the end users is necessary. Table I summarizes questionnaires with regards to users' acceptance. The table also shows result returned by using the application. The evaluation is completed in order to better understand users' perception for qualitative analysis of the results.

It is observed that users have subsequent perception of acceptability, consistency and correctness. In order to compare with the different measurement variables, Table II is produced to show the mean response time of the application's end users. It is found that the request with more precise constraint have greater perceived acceptability, consistency and control than request with less constraints. 
TABLE I. QUESTIONNAIRES WITH REGARDS TO USERS' ACCEPTANCE

\begin{tabular}{|l|l|l|}
\hline No. & $\begin{array}{l}\text { Measurement } \\
\text { Variable }\end{array}$ & Questionnaire \\
\hline 1 & $\begin{array}{l}\text { Perceived } \\
\text { consistency }\end{array}$ & $\begin{array}{l}\text { I find the application provides most often returns } \\
\text { relevant providers of the service. }\end{array}$ \\
\hline 2 & $\begin{array}{l}\text { Perceived } \\
\text { acceptability }\end{array}$ & $\begin{array}{l}\text { I observe that the application returns relevant } \\
\text { service providers considering the contrarian that } \\
\text { I put in looking for a service }\end{array}$ \\
\hline 3 & $\begin{array}{l}\text { Perceived } \\
\text { correctness }\end{array}$ & $\begin{array}{l}\text { I find the application returns correct or relevant } \\
\text { service providers for my requests }\end{array}$ \\
\hline 4 & Perceived risk & $\begin{array}{l}\text { I found that in an emergency case, the } \\
\text { application is able to provide results without } \\
\text { much irrelevant service providers }\end{array}$ \\
\hline
\end{tabular}

TABLE II. MATRIX FOR USER ACCEPTANCE

EVALUATIONQUESTIONNAIRES WITH REGARDS TO USERS' ACCEPTANCE

\begin{tabular}{|l|l|l|l|l|l|}
\hline \multicolumn{2}{|l|}{} & $\begin{array}{l}\text { Perceived } \\
\text { consistency }\end{array}$ & $\begin{array}{l}\text { Perceived } \\
\text { acceptability }\end{array}$ & $\begin{array}{l}\text { Perceived } \\
\text { correctness }\end{array}$ & $\begin{array}{l}\text { Perceive } \\
\text { d risk }\end{array}$ \\
\hline 1 & $\begin{array}{l}\text { Perceived } \\
\text { consistency }\end{array}$ & 2.94 & 2.22 & 1.42 & 4.83 \\
\hline 2 & $\begin{array}{l}\text { Perceived } \\
\text { acceptability }\end{array}$ & 4.2 & 4.25 & 4.27 & 2.85 \\
\hline 3 & $\begin{array}{l}\text { Perceived } \\
\text { correctness }\end{array}$ & 4.3 & 4.37 & 4.10 & 3.1 \\
\hline 4 & $\begin{array}{l}\text { Perceived } \\
\text { risk }\end{array}$ & & & & \\
\hline
\end{tabular}

TABLE III. QUESTIONNAIRES WITH REGARDS TO USERS' FEEDBACK

\begin{tabular}{|l|l|l|}
\hline No & Question & $\begin{array}{l}\text { Average Score } \\
\text { (5:Excellent, 4: } \\
\text { Good, 3:Neutral, } \\
\text { 2:Poor, 1:Bad) }\end{array}$ \\
\hline 1 & $\begin{array}{l}\text { How do you evaluate the overall experience of } \\
\text { the application? }\end{array}$ & 4.2 \\
\hline 2 & $\begin{array}{l}\text { How do you feel the usefulness and usability of } \\
\text { the application? }\end{array}$ & 4.6 \\
\hline 3 & $\begin{array}{l}\text { How do you feel the importance of this } \\
\text { application? }\end{array}$ & 4.9 \\
\hline 4 & $\begin{array}{l}\text { How do like the matchmaking between service } \\
\text { requester and service provider? }\end{array}$ & 3.8 \\
\hline 5 & $\begin{array}{l}\text { How do you feel to recommend your friends to } \\
\text { use this application? }\end{array}$ & 4.4 \\
\hline
\end{tabular}

Table 2 shows the scores generated by the end users of the application. The lower score of mean of control and perceived acceptability shows users' poor acceptance of the application. The moderate score of perceived consistency value reflects that application is potential to use even the end users have given small score in other variables. The reason is that users want some extra result with the context that can provide some benefit to them. Users' satisfaction level of the application is measured using PACMAD[5] usability model. The PACMAD usability model uses ISO standard attributes and the model of Nielsen. PACMAD also includes the cognitive load attribute that is particularly important to mobile applications. The usability model mainly considers three factors (Task, User, and Context of use) in designing mobile applications to find usability of mobile applications. These factors have impact on the final design of the user interfaces of the application. The PACMAD model also considers seven important attributes that are considered to define metrics to evaluate application's usability. However, for the proposed application only two factors: effectiveness and satisfaction to evaluate the usability of the application are considered. Table III shows the questions and the corresponding scores of each question to evaluate satisfaction and effectiveness of the application. There were 22 users who use the prototype application. From the result it shows that users are mostly satisfied with application experience, usefulness and usability, feel that this kind of application is very important for the community service.

\section{CONCLUSION AND FUTURE WORK}

Location-based service providing applications demand is now increasing with the advent of GPS mobile devices. Mobile applications play central rule to bring together the service providers and service users anywhere anytime. The need for looking and obtaining daily needed services while staying at home, workplace, and anywhere anytime is highly demanding. Considering this need this paper presented a mobile application framework that allows an individual to look for services providers around his vicinity. The application provides an individual to find reliable service providers around his vicinity and to know the service providers for various needed. This application will also provide an opportunity to individuals to use their free time for providing services to his community and earn some extra money. It is proved that this application will benefit many stakeholders like elderly people, women at home, a person while traveling in an unknown place, etc. At present the prototype has been developed for the application and users' acceptability is evaluated. The future plan is to develop the application and make available for the users.

\section{REFERENCES}

[1] Keerthi S. Shetty, Sanjay Singh. Cloud Based Application Development for Accessing Restaurant Information on Mobile Device using LBS. Advances in Parallel Distributed Computing, Volume 203 of the series Communications in Computer and Information Science pp 532-543

[2] B. Rao, and L. Minakakis. Evolution of Mobile Location-based Service. Commun. ACM. 2003, 46 (12): 61-65.

[3] H. J. Tsai. Analysis of LBS application development and service system. MIC, Taipei: Market Intelligence \& Consulting Institute. 2006.

[4] M. A. Hossain, A. Nazari, A. Alghamdi, and A. El Saddik. Adaptive Interaction Support in Ambient-aware Environments based on Quality of Context Information. In Multimedia Tools and Applications, 2012.

[5] Rachel Harrison, Derek Flood and David Duce. Usability of mobile applications: literature review and rationale for a new usability model. Journal of Interaction Science 2013, 1:1

[6] C. Pontikakos, T. Glezakos, and T. Tsiligiridis. Location-based services: architecture overview. Proceedings of the International Congress on Information Technology in Agriculture, Food and Environment (ITAFE'05)

[7] F. Zhu, M. Mutka, A. Bivalkar. Toward secure and private service discovery anywhere anytime. Frontiers of Computer Science in China, 2010, Volume 4, Number 3

[8] F. Zhu, M. Mutk, L. Ni. A private, secure and user-centric information exposure model for service discovery protocols. IEEE Transactions on Mobile Computing, 2006, 5(4): 418-429.

[9] [Online] https://www.car2go.com/en/austin/

[10] [Online] https://www.peerby.com/

[11] [Online] https://www.shareyourmeal.net/

[12] [Online] https://sortedlocal.com/

[13] [Online] Accessibility Based Business Models for Peer-to-Peer Markets

[14] [Online] https://www.fixura.com/eu

[15] [Online] http://techcrunch.com/2012/06/07/taskrabbit-leah-busquereassumes-ceo-role/

[16] [Online] https://www.taskrabbit.com/

[17] S. Spiekermann. User Control in Ubiquitous Computing: Design Alternativesand User Acceptance. Shaker Verlag, 2008.

[18] [Online] https://arxiv.org

[19] [Online] https://www.ipcsit.com 